\title{
Role of protein glycosylation in immune regulation
}

\author{
Elizabeth F Hounsell, Michael J Davies
}

Most cell surface and secreted proteins are glycosylated - that is, they have one or more oligosaccharide chains covalently attached to specific amino acids. These oligosaccharides usually make up a significant amount of the hydrodynamic mass of the molecules and also have effects on protein conformation, surface expression, stability, circulating half life, activity, and antigenicity. In addition, oligosaccharide sequences are themselves recognised as antigens and as ligands for carbohydrate binding proteins (lectins). The immune system exemplifies the diversity of oligosaccharide structure and function, which this review will aim to communicate. In particular, the relevance of oligosaccharide heterogeneity, antigenicity, and immune regulatory activity in autoimmunity and microbial pathogenesis will be considered. Firstly, a general description of the structure and three dimensional arrangement of protein glycosylation will be given. Then, we describe the structure of the major glycoprotein effector molecules involved in immune regulation and concentrate on the role of T cell $\gamma \delta$ cells in tuberculosis and rheumatoid arthritis (RA).

\section{General description of protein}

glycosylation (also see Glossary)

Protein glycosylation is of two major types called $\mathrm{N}$ - or O-linked depending on the linkage of the oligosaccharide chain through asparagine $\left(\mathrm{NH}_{2}\right)$ or serine/threonine $(\mathrm{OH})$, respectively. $\mathrm{N}$-linked chains typically have a pentasaccharide core of mannose (Man) and $\mathrm{N}$-acetylglucosamine (GlcNAc) residues with additional mannose residues (high mannose chains) or backbone galactose- $N$-acetylglucosamine sequences with and without chain terminating sialic acid residues (complex chains). Hybrid chains are defined as those having some high mannose branches and some complex-type sequences. The core and backbone residues of complex chains are variously decorated with blood group and related antigenic sequences involving substitution with fucose, (Fuc), $N$-acetylgalactosamine (GalNAc), and galactose (Gal). ${ }^{12}$ The presence of the different chains can be distinguished not only by chemical composition but also by their susceptibility to enzyme digestion - all are released by peptide$\mathrm{N}$-glycosidase $\mathrm{F}$, whereas endoglycosidase $\mathrm{H}$ only releases high mannose chains.

O-linked glycosylation discussed in this article is characterised by core regions based on $\mathrm{N}$-acetylgalactosamine linked to protein, with galactose, $\mathrm{N}$-acetylglucosamine, or $\mathrm{N}$-acetylgalactosamine attached. ${ }^{1-4}$ Extension of the chains is by substitution patterns similar to those of the outer branches of $\mathrm{N}$-linked glycosylation (although there are differences). In both chains the diversity of oligosaccharide sequences is manifest in the large number of ways the monosaccharides can be linked together (that is, through 1-4 hydroxyl groups, with and without branching, in $\alpha$ or $\beta$ configuration, etc). Each linkage has a particular set of allowed conformations in solution which provide specific orientations of functional groups for molecular recognition. Such epitopes usually extend over a tri- to heptasaccharide sequence, but topographical epitopes caused by folding back of long carbohydrate chains onto themselves or onto protein are possible. In addition, the oligosaccharide cores of O-linked chains are in close association with the protein backbone, which strongly influences protein conformation and oligosaccharide-protein antigenicity. ${ }^{2}$ Often multiple $\mathrm{O}$-glycosylation sites are clustered in one region of the protein to accentuate these conformational effects (for example, CD8 discussed below).

$\mathrm{N}$-linked chains are in general less stereochemically restricted around the proteinoligosaccharide linkage than their O-linked counterparts, and, in addition, have considerable flexibility at branch points within the chain. The oligosaccharide moieties, therefore, sample a large amount of conformational space, but in some cases they may be restrained by interaction with the protein backbone or adjacent oligosaccharides attached to the same protein. The paradigm for protein-to-N-glycosylation interaction is the Fc region of IgG where electron density for oligosaccharides has been shown by $x$ ray crystallography which can be interpreted as constraints by the protein to impose a single conformational state. ${ }^{5}$ In other glycoproteins that have been characterised by $x$ ray crystallography the oligosaccharide conformation could not be discerned at high resolution - for example, studies of the major histocompatibility complex (MHC) glycoprotein molecule HLA-A2. ${ }^{6}$ For still further glycoproteins, crystals of sufficiently high quality for $x$ ray crystallography are not formed unless some of the glycosylation is modified. This can be for the reasons already mentioned - that is, large hydrodynamic volume (in particular when multiple glycosylation is present); effects on protein conformation; or, inherent oligosaccharide flexibility. An additional factor, discussed next, is the microheterogeneity of oligosaccharide structure at each glycosylation site within a protein. Because of the difficulties of their visualisation by $x$ ray studies the characterisation of protein 
glycosylation has largely relied on enzymatic, gel, and chromatographic methods of analysis with, when possible, high resolution physicochemical techniques (in particular, mass spectrometry and nuclear magnetic resonance spectroscopy)..$^{2-4} 7$

\section{Microheterogeneity of oligosaccharide sequences of glycoproteins}

All glycoproteins exhibit heterogeneity such that they exist as a population having a spectrum of oligosaccharide sequences (glycoforms). Variation occurs in the number and length of branches (or antennae) leading from the cores, together with alterations in sequence and peripheral substitutions. Of relevance to the present article is the documentation of the glycoforms of IgG where a large number of different biantennary $\mathrm{N}$-linked chains were found, including some having short chains exposing GlcNAc $\beta$ residues to which $\mathrm{Gal}$ residues and additional substitutions are normally linked. ${ }^{8}$ The presence of these chains, termed $\mathrm{Gal}_{\mathrm{o}}$ is suggested to be a marker of RA that may be functional by reducing the intramolecular oligosaccharide-to-protein interaction discussed above or by effecting binding to GlcNAc $\beta$ specific endogenous lectins, or both. This binding would have to be specific to the GlcNAc $\beta 1-6 / 4 / 2 \mathrm{Man}$ sequence as GlcNAc $\beta 1-3 \mathrm{Gal}$ and GlcNAc $\alpha 1-4 \mathrm{Gal}$ are found quite commonly as chain terminating groups in mucins. ${ }^{3}$

The studies quoted in reference 8 were carried out on IgG pooled from human serum. From other studies it is known that glycoproteins from single donors can also show considerable heterogeneity - for example, more than 250 different glycoforms from the Tamm-Horsfall proteins of the urine of one donor. ${ }^{9}$ There is also considerable variation in cell-cell glycosylation - for example, in glycoproteins from single cell lines. ${ }^{10}$ The structural changes in IgG are also mirrored in cell studies from patients with $\mathrm{RA}^{11}$ or from the lpr autoimmune mouse model. ${ }^{12}$ These studies provide support for the contention that particular clones of B cells can be stimulated to express immunoglobulins of a restricted phenotype. ${ }^{13}$ Since the original observations of $\mathrm{Gal}_{\circ}$ in rheumatoid patients ${ }^{8}$ several other immune disorders, granulomatous-type diseases such as tuberculosis, and age matched controls have shown the prevalence of this type of IgG glycosylation." ${ }^{11}$ Although, in general, there is a large variability in the glycosylation of glycoproteins in normal and diseased states, the $\mathrm{Gal}_{\circ}$ phenotype remains relatively restricted to IgG. The relevance of this observation within the context of the complexity of autoimmunity remains obscure. This review explores other areas where protein glycosylation may play a part in immune regulation.

Direct role of protein glycosylation

In addition to the heterogeneity in the types of glycoprotein chains discussed above, there are further glycosylation patterns found in, for example, parasite and mammalian glycophosphatidylinositol lipid anchors ${ }^{14}$ and bacterial glycoconjugates, including cell wall peptidoglycans, capsular polysaccharides, and O-antigen-type specific lipopolysaccharides. ${ }^{15} 16$ These molecules are highly antigenic, but in the case of lipopolysaccharides and peptidoglycan are more likely to exert their arthritogenic affect by mechanisms involving direct mitogenicity. ${ }^{15}$ The mammalian proteoglycans are an additional type of glycosylation which needs to be discussed in this context. One of the initial responses in the rheumatoid joint is breakdown of the proteoglycans which, together with collagen, make up cartilage. Hyperimmunisation with host proteoglycans will lead to experimental arthritis. ${ }^{17}$ Proteoglycans are classically very high molecular weight molecules of different uronic acid-hexosamine repeating disaccharide sequences having multiple variable sulphation. ${ }^{18}$ Relatively short regions of proteoglycan sequences, however, can also be found on membrane-type glycoproteins - for example, the invariant chain of class II $\mathrm{MHC}^{19}$ and lymphocyte antigen CD $44 .^{20}$ Therefore besides direct damage to the joint, the enzymes induced in arthritis which degrade proteoglycans may also directly affect $\mathrm{T}$ cell function. Proteoglycans are also common constituents of secretory granules of a variety of haemopoietic cells. ${ }^{21}$ In mast cells evidence is accumulating for their function during degranulation in controlling the release of mast cell proteases, ${ }^{22}$ which are the mediators of allergic inflammatory reactions. In addition, proteoglycans at endothelial cell membranes are necessary for an intact microvasculature, the breakdown of which is an essential component of the rheumatoid process. ${ }^{23}$

Other glycoproteins are being increasingly implicated in the inflammatory process - in particular, the recruiting of neutrophils to areas of endothelial cell damage. Studies have shown that particular oligosaccharide structures on a subset of neutrophil glycoproteins are recognised by the selectin ELAM-1 induced on activated endothelial cells. ${ }^{24}$ The major oligosaccharide structure involved, called sialyl Lewis $\mathrm{X}$, belongs to a family of previously characterised oligosaccharide differentiation antigen ${ }^{25}$ which have now found a role in cellular interactions. These interactions are influenced by cytokines such as tumour necrosis factor. ${ }^{26}$ Other cytokines, the interleukins IL-1 and IL-2, have been shown to have lectin properties and respectively bind to Tamm-Horsfall glycoprotein ${ }^{27}$ (also called uromodulin when found in the urine of pregnant females with more glycosylation than the Tamm-Horsfall glycoprotein discussed above) and high mannose oligosaccharides. ${ }^{28}$ This may explain the well known immunosuppressive effect of the oligosaccharides of Tamm-Horsfall glycoprotein/uromodulin and also of the high mannose chains of yeast. A second mechanism for the immunosuppressive effects of polysaccharides of microbial origin is 
their uptake by macrophages and disruption of the normal paths of antigen presentation. ${ }^{29}$ Mention should also be made here of $(a)$ the lectin properties of $\mathrm{IgD}^{30} ;(b)$ the strong homologies between a rat IgE binding protein and galactose binding proteins such as CBP35 and Mac-2 macrophage antigen ${ }^{31}$; and $(c)$ the glycosylation inhibiting factor, which alters the glycosylation of $\mathrm{IgE}$ binding proteins causing selective suppression of IgE synthesis. ${ }^{32}$

\section{Effect of glycosylation on immune protein function}

In addition to the specific functions of oligosaccharides in immune regulation, glycosylation has several regulatory effects on protein function and recognition. The oligosaccharide chains of glycoproteins tend to cover a large surface area inhibiting immune recognition and processing of the underlying protein. Many of the effector molecules in immune regulation, including the immunoglobulins mentioned above, are glycosylated. The cytokine receptors so far characterised are glycoproteins, as are some of the cytokines themselves. ${ }^{33}$ Oligosaccharides are known to influence the conformation of the protein to which they are attached and this is particularly true of the multiple O-glycosylation found, for example, on the receptor for IL-2 ${ }^{34}$ and on CD8. The first evidence for the importance of O-glycosylation in lymphocyte antigens was reported for CD $45 .^{35}$ For CD8 it has been shown ${ }^{36}$ that $\mathrm{O}$-glycosylation must be removed before crystallisation can take place for $x$ ray crystallography studies. Interestingly, the related molecule $\mathrm{CD} 4$, which has a role equivalent to that of CD8 in their respective binding to class I and class II MHC molecules, ${ }^{37}$ has a very different glycosylation pattern with no reported O-glycosylation but having four possible N-linked sites, the occupancy of which is a prerequisite for correct folding and membrane expression. ${ }^{38}$ MHC molecules are themselves glycosylated and this can influence antigen presentation. ${ }^{39}$ In fig 1 we have chosen to illustrate the relative sizes and orientation of a single oligosaccharide chain as present on the human class I MHC molecule HLA-A2. It depicts the minimum sized N-linked complex chain which in the native molecule could have additional branches and peripheral substitution. As discussed, most glycoproteins have more than one glycosylation site. Figure 2 presents a

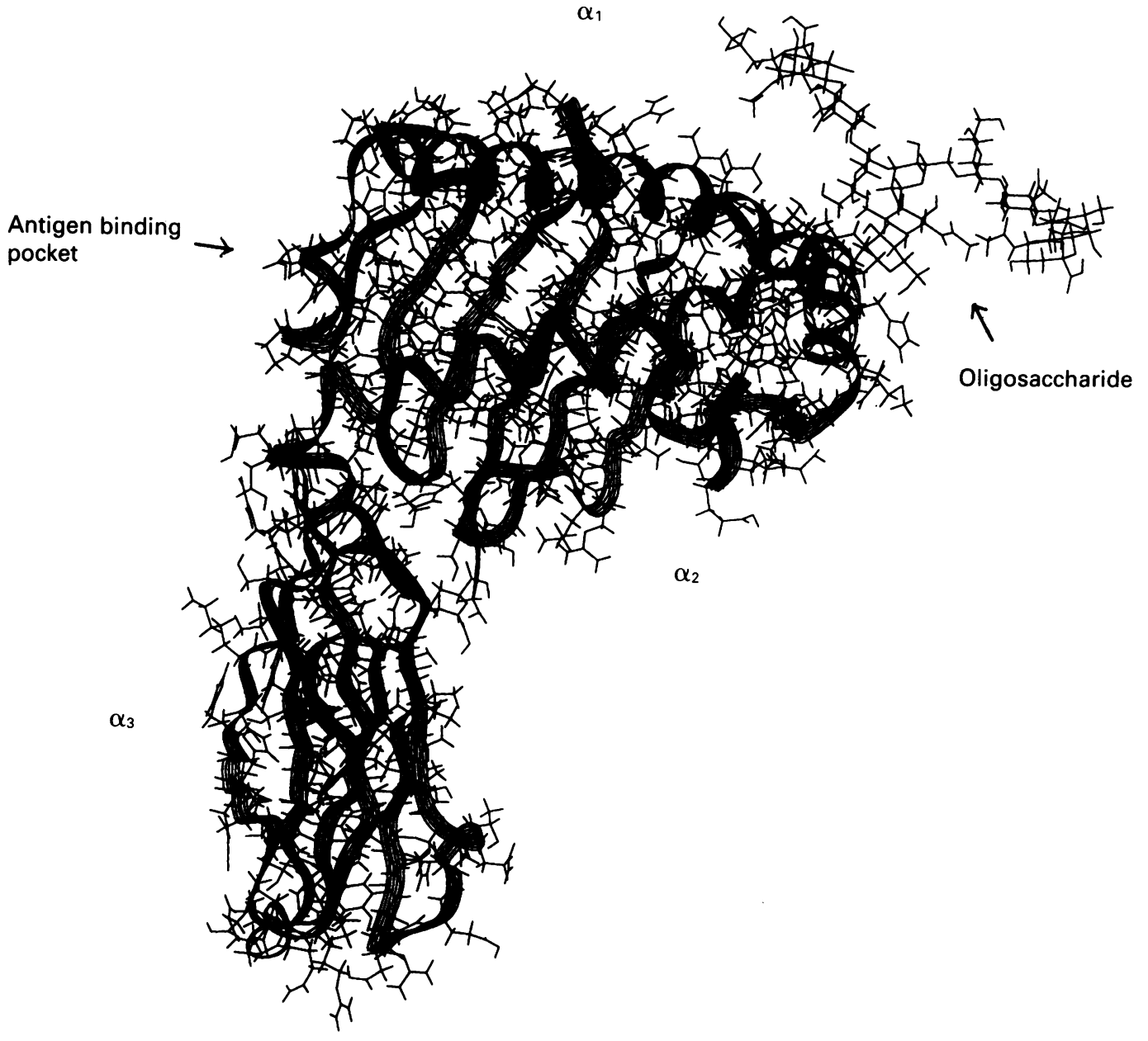

Figure 1 A computer graphics molecular model of MHC class I HLA-A2 $\alpha_{1}-\alpha_{3}$ domains (270 amino acids) taken from

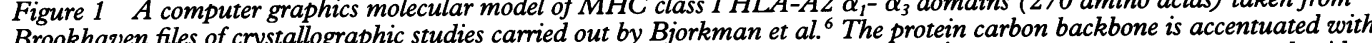
Brookhaven files of crystallographic studies carried out by Bjorkman et al. The protein carbon backbone is accentuated with a ribbon. The $\alpha_{1}$ and $\alpha_{2}$ region $\alpha$ helices surround the antigen binding pocket. A disialyated biantennary nonasaccharide is attached at the consensus $N$-linked glycosylation site, Asn 86 (top right), at the end of the $\alpha_{1} \alpha$ helix. This shown. Modelling was carried out using Biosym software on a silicon graphics IRIS workstation. 


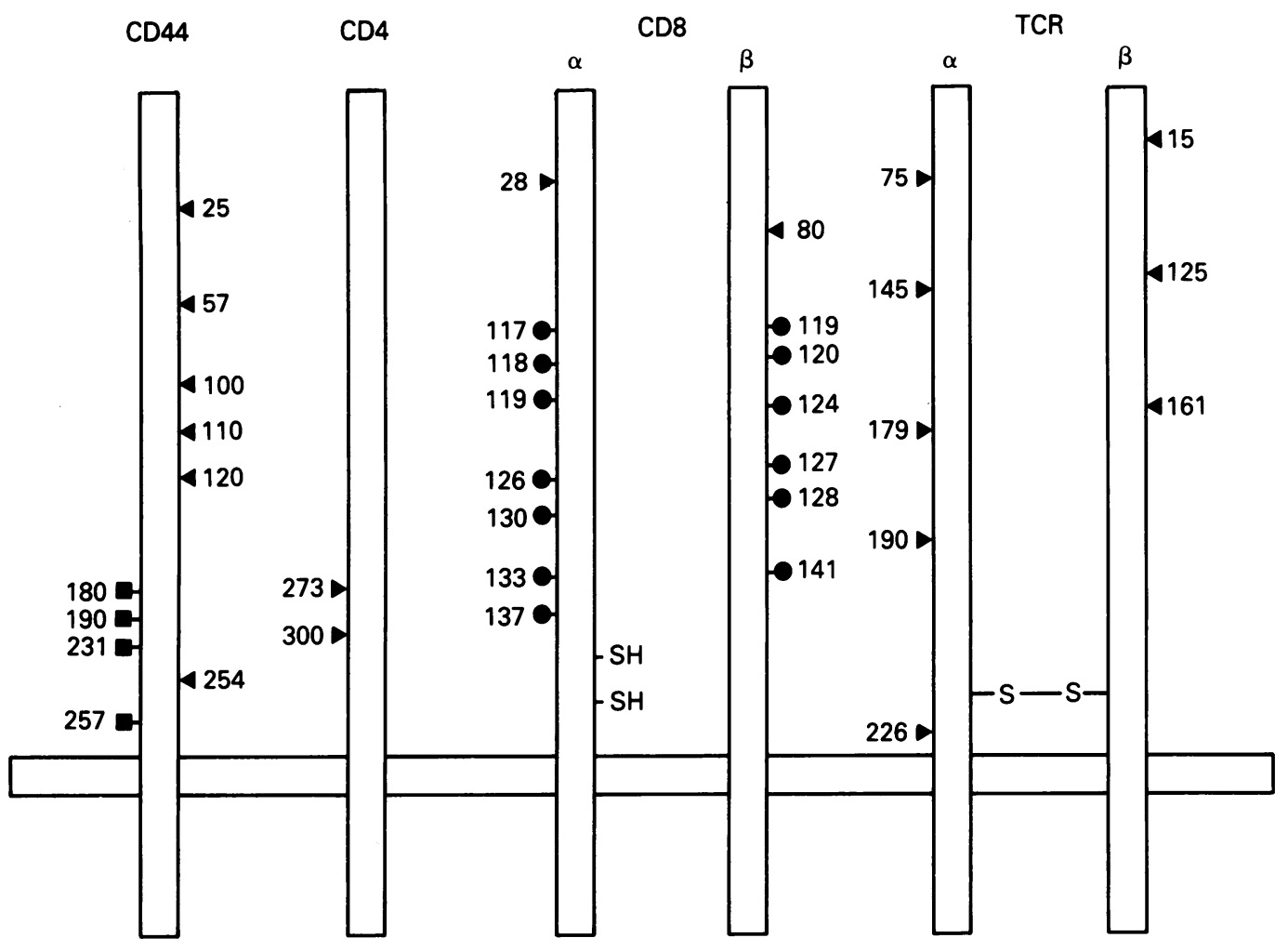

Figure 2 The glycosylation patterns of the human $T$ cell glycoproteins CD44, CD4, CD8 ( $\alpha \beta$ heterodimer), and the $T$ cell receptor (HPB-MLT $\alpha$ chain, HPB-ALL $\beta$ chain). Consensus $N$-glycosylation sites are denoted by $\square$, characterised $O$-glycosylation sites by $\boldsymbol{Q}$, and potential proteoglycan attachment sites by $\boldsymbol{Q}$. SH represents free cysteines capable of forming interchain disulphide bridges and $-S-S$ represents interchain disulphide bridges.

synopsis of the oligosaccharide chains of CD44, CD4, CD8 $\alpha \beta$, and the $T$ cell receptor (TCR) $\alpha \beta$ chains showing their various glycosylation patterns taken from references $20,36,38$, and $40-43$.

Type 1

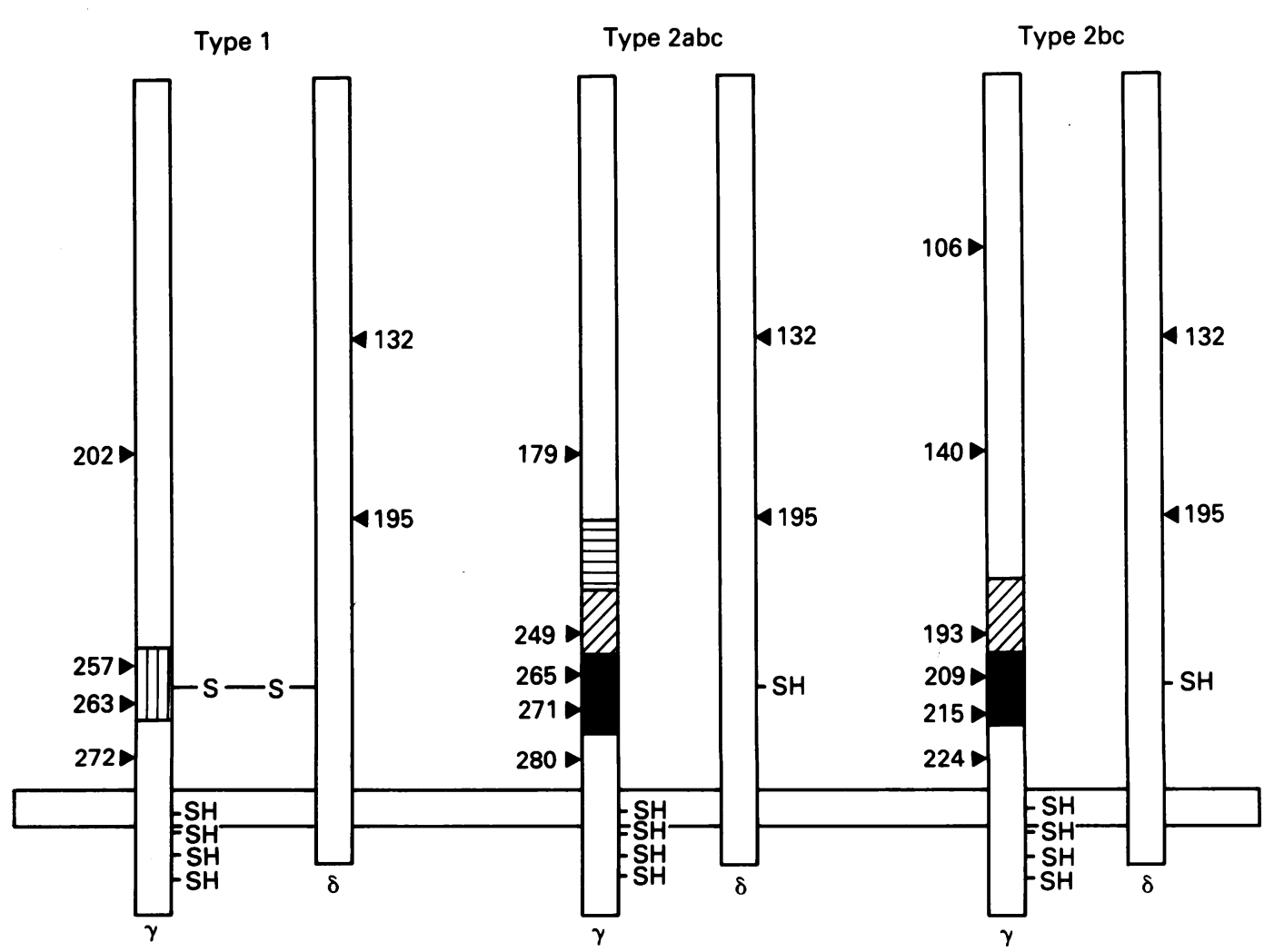

A more complicated pattern of cell specific glycosylation of $\mathrm{T}$ cell $\gamma \delta$ receptors has emerged (fig 3), which we discuss here in full to illustrate the type of diversity encountered, together with the evidence implicating this $\mathrm{T}$

Figure 3 The diversity of $\gamma \delta T$ cell receptor structures; glycosylation sites are classified as in fig 2 . 血 represents the $C \gamma 1 C 2$ exon; 目 represents the $C \gamma 2 C 2$ exon copy $a ; \square$ represents the $C \gamma 2 C 2$ exon copy b; represents the $C \gamma 2 C 2$ exon copy c. 
cell subset in the aetiology of RA and tuberculosis.

\section{$T$ cell $\gamma \delta$ receptor structure}

The TCR $\delta$ chain is a polypeptide of 40 kilodalton size with two $\mathrm{N}$-linked glycosylation sites (one high mannose oligosaccharide and one complex oligosaccharide, as determined by endoglycosidase $\mathrm{H}$ and peptide $\mathrm{N}$-glycanase $\mathrm{F}$ digests). ${ }^{44}$ In addition, there are two intramolecular disulphide bridges and potential for one intermolecular disulphide bridge ${ }^{44}{ }^{45}$ In T cell lines $\gamma$ chains exhibit much more structural diversity, being expressed as one of three forms. All three forms have two intramolecular disulphide bridges and at least two potential $\mathrm{N}$-glycosylation sites. The type 1 receptor was first isolated from a peripheral blood lymphocyte cell line. ${ }^{45}$ This form expresses two glycoforms of the $\gamma$ chains, a 40 and a 36 kilodalton form, both forms containing four $\mathrm{N}$-linked glycosylation sites. ${ }^{46}$ Treatment with endoglycosidase $\mathrm{H}$ reduced both glycoforms to a core peptide of 31 kilodaltons. ${ }^{45}$ This indicates differential glycosylation of the two peptides, notably in the distribution of high mannose and hybrid oligosaccharides. The type 1 receptor uses the $C \gamma 1$ gene. Within this, one copy of the C2 exon is expressed, containing two consensus $\mathrm{N}$-glycosylation sites and a cysteine residue. This cysteine is able to crosslink with the cysteine of the $\delta$ chain forming a disulphide bridge. ${ }^{44} \mathrm{It}$ is this feature which is the main distinguishing characteristic of the type 1 receptor.

In addition to the type 1 form, two nonintermolecular disulphide linked forms of the receptor have been described. ${ }^{44}{ }^{45}$ The $\delta$ chains are similar to those expressed by the type 1 receptor, but the $\gamma$ chains show significant diversity in their constant regions. ${ }^{44}$ Both forms use the $\mathrm{C} \gamma 2$ gene for their constant region. The 2abc form expresses three copies of the C2 exon (copies a, b, and c). The resulting polypeptide has a size of 55-60 kilodaltons, which reduces to 40 kilodaltons on endoglycosidase $\mathrm{H}$ treatment, again showing differential glycosylation and the probable use of all five consensus N-glycosylation sites. ${ }^{44} 4748$

The second non-disulphide linked form of the receptor (type $2 \mathrm{bc}$ ) expresses two copies of the $\mathrm{C} 2$ exon (copies b and c). ${ }^{44}$ This results in a glycosylated peptide of 40 kilodaltons, which reduces to 35 kilodaltons, on endoglycosidase $\mathrm{H}$ treatment. The amino acid sequence gives a theoretical non-glycosylated size of 34.8 kilodaltons, which together with tunicamycin data (an inhibitor of N-linked glycosylation) shows the glycosylation to be essentially all $\mathrm{N}$-linked. ${ }^{44}$ The 5 kilodalton loss in molecular weight indicates that unlike the type $2 \mathrm{abc}$ receptor only two of the six possible glycosylation sites are used. The differences in the number of glycans added can be explained by the fact that the protein encoded by the $\mathrm{C} 2 \mathrm{a}$ exon copy has an altered secondary or tertiary structure making more of the 2abc $\gamma$ chain consensus $\mathrm{N}$-glycosylation sites accessible. ${ }^{47}$

Expression of the type 1 receptor is predominant in peripheral blood lymphocytes, although if the type 2 receptors are expressed, types 1 and 2 are usually found in equal proportions. ${ }^{47}$ This diversity of $\mathrm{T}$ cell receptors is unique to $\gamma \delta \mathrm{T}$ cells and as yet no distinct functional roles have been attributed to either TCR type, though a report has suggested different cytoskeletal organisation and morphology between the $\mathrm{C} \gamma 1$ and $\mathrm{C}_{\gamma} 2$ forms. ${ }^{49}$

Like $\alpha \beta$ TCRs, $\gamma \delta$ TCRs are associated with the CD3 glycoprotein to facilitate cell signalling and activation. The CD3 $\gamma \delta \epsilon$ peptide cores are the same for both $\mathrm{T}$ cell subsets $(\alpha \beta$ and $\gamma \delta) .{ }^{50}$ However, glycosylation of the CD3 3 subunit is different. In $\alpha \beta$ T cells the $\mathrm{CD} 3 \delta$ subunit carries one high mannose and one complex oligosaccharide, ${ }^{51}$ whereas in $\gamma \delta \mathrm{T}$ cells both oligosaccharides are fully processed to the complex form. ${ }^{50} \gamma \delta \mathrm{CD} 3$ seems to increase intracellular calcium on triggering and is a substrate for protein kinase C activation. ${ }^{52}$ Thus if the different glycosylation is important it may function in the regulation of $\mathrm{T}$ cell signalling via the $\gamma \delta$ TCR/CD3 pathway.

\section{Role of TCR $\gamma \delta$ cells in antigen and superantigen recognition}

Heat shock proteins are the major antigen described to be recognised by $\gamma \delta \mathrm{T}$ cells. In both a live and heat killed Mycobacterium tuberculosis infection model, $\gamma \delta \mathrm{T}$ cells produced interferon $\gamma$, granulocyte-monocyte colony stimulating factor, IL-3, and tumour necrosis factor $\alpha .{ }^{54}$ The nature of the dominant antigen or antigens recognised remains to be characterised fully as up to 400 different components may be involved, ${ }^{55}$ but the mycobacterial 65 kilodalton heat shock protein (hsp65) is a major contender ${ }^{56} 57$ and, in particular, a peptide corresponding to residues 181-195. ${ }^{58}{ }^{59}$ Heat shock proteins are a highly conserved set of proteins with both bacterial and mammalian homologues. The 60 kilodalton family (including $M$ tuberculosis hsp65) is thought to influence the folding and trafficking of mitochondrial proteins. ${ }^{6061}$

The 65 kilodalton heat shock protein has been described as a possible antigen in several autoimmune disorders. It has been suggested to be a putative $\gamma \delta \mathrm{T}$ cell ligand on Daudi cells $^{62}$ and a ligand on $B$ cells in lupus nephritis. ${ }^{63}$ Rheumatoid arthritic synovial fluid $\gamma \delta \mathrm{T}$ cells reactive to $M$ tuberculosis were first isolated in $1989,{ }^{64}$ with one clone reacting to the hsp65 of $M$ bovis-BCG. An earlier rat model of adjuvant arthritis had shown the antigenicity of hsp65 peptide $180-188,{ }^{65}$ though this epitope is only present in the bacterial protein and not its mammalian homologue. More recently, both $\gamma \delta$ and $\alpha \beta \mathrm{T}$ cell clones have been isolated, which are stimulated by both mycobacterial and human hsp65, supporting the possibility of hsp65 involvement in autoimmune disorders. ${ }^{66} 67$ Data for hsp65 as a major antigen of RA are not entirely conclusive. ${ }^{68} \mathrm{~A}$ recent review has shown that recombinant hsp65 from Escherichia coli also contained small quantities of $E$ coli derived antigens. ${ }^{69}$ Thus stimulation 
of rheumatoid $\mathrm{T}$ cells by the recombinant hsp65 may in fact be by contaminating $E$ coli antigens. Coupled with this, a second group has found that highly purified $M$ bovis-BCG hsp65 is poorly stimulatory, leading the authors to conclude that hsp65 is not a major antigen for rheumatoid synovial fluid $\mathrm{T}$ cells. ${ }^{70}$ The role of hsp65 in RA is thus not clear cut and it may be that hsp65 continues the degenerative disease process after stimulation by a different antigen. ${ }^{71}$ It is of interest here that heat shock protein may mimic the MHC in a similar manner to that proposed for HIV gp120. ${ }^{72} 73$

No alternative mycobacterial antigens of possible relevance for human RA have yet been characterised. Mycoplasmal mitogens have been proposed in murine models. ${ }^{74}$ Superantigen stimulation has been used to explain the increased usage of V $\beta 14 \alpha \beta \mathrm{T}$ cells in $\mathrm{RA}^{76}$ In addition, the superantigen staphylococcal enterotoxin $\mathrm{D}$ has been shown to stimulate CD4 V $\beta 6 \alpha \beta$ T cells to produce rheumatoid factors. ${ }^{77}$ There is also evidence that superantigens may stimulate $\gamma \delta \mathrm{T}$ cells in RA: $V \gamma 9 \delta 2 \mathrm{~T}$ cell clones from rheumatoid arthritic synovial fluid have been shown to recognise a short tetanus toxin peptide in the context of MHC class $\mathrm{II}^{78}$; this $\mathrm{V} \gamma 9 \delta 2$ subset may be stimulated by the acetone precipitable fraction of $M$ tuberculosis. ${ }^{78} 79$ There is also evidence for clonal expansion of $\mathrm{V} \gamma 9 \mathrm{~T}$ cells in the synovial fluid of patients with RA. ${ }^{80}$

Similarly, in $M$ tuberculosis infection there is increasing evidence that hsp65 is not a major $\gamma \delta \mathrm{T}$ cell antigen, ${ }^{81}$ and indeed there is some evidence that it may be a poor $M$ tuberculosis antigen in general. ${ }^{82}$ The major subset of $\gamma \delta \mathrm{T}$ cells which expands in response to $M$ tuberculosis is $\mathrm{V} \gamma 9 \delta 2$, which predominantly express the $\mathrm{C} \gamma 1$ form of the TCR discussed above. ${ }^{83} 84$ The same $V \gamma 9$ subset has been shown to be stimulated by the superantigen, staphylococcal enterotoxin $A,{ }^{85}$ which requires the presence of the MHC class II. This is directly analogous to the activation of $\alpha \beta$ cells by superantigens. ${ }^{86} \mathrm{~A}$ second $\mathrm{V} \gamma$ 9-seeking superantigen has been isolated from $M$ tuberculosis, ${ }^{86} 87$ again requiring MHC class II. The antigen seems to be a low molecular weight, protease resistant ligand which loses its antigenicity on incubation with the plant lectins UEA1, SBA, and DBA. Thus it has been postulated that the active components are glycosylated determinants having chain terminating $\alpha$-linked fucose and GalNAc $\alpha(1-$ 3) GalNAc for which these lectins are specific. ${ }^{87}$ This is important not only from the point of view of $M$ tuberculosis infection but is the first time a possible non-protein superantigen has been described.

The mechanism by which antigens are presented to $\gamma \delta \mathrm{T}$ cells remains largely unresolved. Conflicting reports exist on the requirement for $\beta_{2}$ microglobulin and hence class I restriction of $\gamma \delta \mathrm{T}$ cells, ${ }^{88}{ }^{89}$ though the requirement may depend on the $T$ cell type studied. Restriction by non-classical class I molecules including Qa-1, has been shown. ${ }^{90}$ The initial discovery of $\gamma \delta \mathrm{T}$ cells in rheumatoid synovial fluid noted the requirement of antigen presenting cells for stimulation by mycobacterial antigens, but this was suggested not to be class I or class II restricted. ${ }^{64}$ Later a class II restricted $\mathrm{V} \gamma 9 \delta 2 \mathrm{~T}$ cell response was characterised against a tetanus toxin peptide. ${ }^{78}$ However, only a small percentage of $\gamma \delta \mathrm{T}$ cells are $\mathrm{CD} 4+$; the majority express either CD8 $\alpha$ chains only, or are CD4-CD8-, and it has been suggested that CD4+ $\gamma \delta \mathrm{T}$ cells are more likely to be a fetal T cell subset which has persisted postnatally. ${ }^{91}$ In general, $\gamma \delta$ and $\alpha \beta$ T cells produce a similar range of cytokines, ${ }^{92}$ but the proposed minor subset of CD4+ $\gamma \delta \mathrm{T}$ cells shows production of IL-2 and granulocyte-monocyte colony stimlating factor and low levels of cytotoxic activity, whereas the CD4 $-\gamma \delta \mathrm{T}$ cells exhibit lower levels of cytokine production and a higher cytotoxic activity. ${ }^{93}$ Based on this $\gamma \delta \mathrm{T}$ cells can be subdivided into a CD4+ 'helper' subset and a CD4- 'cytotoxic' subset.

\section{Conclusion}

Study of the possible role of superantigens in autoimmune disorders has recently become the vogue. Care should be exerted in interpretation of the data, however, owing to the complexity of the interactions of the effector molecules involved in immune regulation. An important aspect of these interactions is the role of glycosylation in regulating glycoprotein activity, antigenicity, and recognition.

Protein glycosylation may be involved in several stages in the aetiology of RA: (a) initiating antigen; $(b)$ control of $\mathrm{T}$ cell interactions; (c) control of antibody function; $(d)$ microvasculature breakdown; (e) breakdown of synovial gel/water structure; and $(f)$ specific signals to inflammatory cells.

Of crucial importance is the role that proteoglycan sequences have in maintaining the endothelial cell surface barrier, the physicochemical properties of the synovium, and cartilage structure. The release of enzymes which breakdown these proteoglycans could also directly affect lymphocyte immune function by altering cell surface molecules and intracellular trafficking.

\section{Glossary}

CD: Clustered Determinant lymphocyte antigens.

Consensus $\mathrm{N}$-glycosylation site: The nitrogen $(\mathrm{N})$ of the Asn amino acid in the sequence Asn-X-Ser/Thr has the potential to be glycosylated, where $\mathrm{X}$ is any amino acid except proline.

$\mathrm{N}$-linked protein chains: high mannose complex hybrid

O-linked glycoprotein chains: The hydroxyl group of any Ser or Thr amino acid usually in high Ser/Thr/ Pro- containing regions is glycosylated.

Peptidoglycan: Repeating bacterial cell wall polymer of amino acids, muramic acid, and $\mathrm{N}$-acetylglucosamine.

Polysaccharides: In addition to plant (e.g. cellulose) and 
mammalian (e.g. glycogen) polymers, bacteria have diverse long chain molecules of often complex repeats defined as: (a) capsular antigens (b) O-antigen lipopolysaccharide (LPS).

Proteoglycan: Components of mammalian extracellular matrix, membrane cell surface molecules, secretory granules, and cartilage.

Selectin: Mammalian carbohydrate binding protein also called leccams (lectin cell adhesion molecules).

1 Hounsell E F, Feizi T. Gastrointestinal mucins. Structures and antigenicities of their carbohydrate chains in health and disease. Med Biol 1982; 60: 227-36.

2 Hounsell E F, Davies M J, Renouf D V. Studies of oligosaccharide and glycoprotein conformation. Biochem Soc Trans 1992; 20: 259-63.

3 Hounsell E F, Lawson A M, Stoll M S, et al. Characterisation by mass spectrometry and $500-\mathrm{MHz}$ proton nuclear magnetic resonance spectroscopy of penta- and hexasaccharide chains of human foetal gastrointestinal mucins (meconium glycoproteins). Eur $\mathcal{F}$ Biochem 1989; 186: 597-610.

4 Chai W, Hounsell E F, Cashmore G C, et al. Neutral oligosaccharides of bovine submaxillary mucin. A combined mass spectrometry and ${ }^{1} \mathrm{H}-\mathrm{NMR}$ study. Eur $\mathcal{F}$ Biochem 1992; 203: 257-68.

5 Rudd P M, Leatherbarrow R J, Rademacher T W, Dwek $\mathrm{R}$ A. Diversification of the IgG molecule by oligosaccharides. Mol Immunol 1991; 28: 1369-78.

6 Bjorkman P J, Saper M A, Samraoui B, Bennett W S Strominger J L, Wiley D C. Structure of the human clas I histocompatibility antigen, HLA-A2. Nature 1987; 329 506-12.

7 Hounsell E F. Structural and conformational characterization of carbohydrate differentiation antigens. Chem Soc Rev 1987; 16: 161-85.

8 Sutton D L, Fernandes A, Leung D, et al. Primary sequence of the $N$-linked oligosaccharides associated with IgG Nature 1985; 316: 452-7.

9 Hård $\mathrm{K}$, van Zadelhoff $\mathrm{G}$, Moonen $\mathrm{P}$, Kamerling $\mathrm{J} \mathrm{P}$, Vliegenthart J F G. The Asn-linked carbohydrate chains of human Tamm-Horsfall glycoprotein. Novel sulfated and novel GalNAc-containing N-linked carbohydrate chains. Eur f Biochem. 1992; 209: 895-915.

10 Hard K, Damm J B L, Spruijt M P N, et al. The carbohydrate chains of the $\beta$ subunit of human chorionic gonadotropin produced by the choriocarcinomas cell line BeWo. Novel O-linked and novel bisecting-GlcNAccontaining N-linked carbohydrates. Eur f Biochem 1992; 205: $785-98$.

11 Bodman K B, Sumar N, MacKenzie L E, et al. Lymphocytes from patients with rheumatoid arthritis produce agalactosylated IgG in vitro. Clin Exp Immuno 1992; 88: 420-3.

12 Mizuochi T, Hamako J, Nose M, Titani K. Structural changes in the oligosaccharide chains of IgG in autoimmune MRL/Mp-lpr/lpr mice. F Immunol 1990; 145: $1794-8$

13 Haynes G A, Maini R N, Malcolm A D B. Immunoglobulin $\mathrm{V}$ genes expression and $\mathrm{mRNA}$ sequencing in rheumatoid genes expression an Dis 1990; 49: 460-8.

14 Ferguson M A J. Lipid anchors on membrane proteins. Current Opinions in Structural Biology 1991; 1: 522-9.

15 Stimpson S A, Esser R E, Carter P B, Balfour Sartor R, Cromartie W J, Schwab J H. Lipopolysaccharide induces recurrence of arthritis in rat joints previously injured by peptidoglycan-polysaccharide. $f$ Exp Med 1987; 165: $1688-702$.

16 Jennings $\mathrm{H}$. Capsular polysaccharides as human vaccines. Adv Carbohydr Chem Biochem 1983; 41: 155-208.

17 Leroux J-Y, Poole A R, Webber C, et al. Characterization of proteoglycan-reactive $\mathrm{T}$ cell lines and hybridomas from mice with proteoglycan-induced arthritis. $f$ Immunol mice with proteogly

18 Poole A R. Proteoglycans in health and disease: structure and functions. Biochem 7 1986; 236: 1-14.

19 Sant A J, Cullen S E, Giacoletto K S, Schwartz B D Invariant chain is the core protein of the Ia-associated chondroitin sulfate proteoglycan. 7 Exp Med 1985; 162: 1916-34.

20 Stamenkovic I, Amiot M, Pesando J M, Seed B. A lymphocyte molecule implicated in lymph node homin is a member of the cartilage link protein family. Cell 1989 56: $1057-62$.

21 Steward W P, Christmas S E, Lyon M, Gallagher J T. The synthesis of proteoglycans by human $T$ lymphocytes. Biochim Biophys Acta 1990; 1052: 416-25.

22 Le Trong $\mathrm{H}$, Newland G F J, Miller H R P, Charbonnea $\mathrm{H}$, Neurath $\mathrm{H}$, Woodbury R G. Amino acid sequence of a mouse mucosal mast cell protease. Biochemistry 1989 28: 391-5.

23 Lopes-Virella M F, Virella G. Immunological and microbiological factors in the pathogenesis of atheroscler
24 Lowe J B, Stoolman L M, Nair R P, Larsen R D, Berhend T L, Marks R M. ELAM-1-dependent cell adhesion to vascular endothelium determined by a transfected human fucosyltransferase cDNA. Cell 1990; 63: 475-84

25 Feizi T. Cell-cell adhesion and membrane glycosylation. Current Opinions in Structural Biology 1991; 1: 766-70.

26 Gamble J R, Smith W B, Vadas M A. TNF modulation of endothelial and neutrophil adhesion. In: Beutler B, ed. Tumour necrosis factors: the molecules and their emerging role in medicine New York: Raven Press, 1992: 65-86.

27 Muchmore A V, Decker J M. Evidence that recombinan ILl A exhibits lectin-like specificity and binds to homogeneous uromodulin via N-linked oligosaccharides. homogeneous uromodulin via

28 Sherblom A P, Sathyamoorthy N, Decker J M, Muchmore A V. IL-2, a lectin with specificity for high mannose glycoproteins. F Immunol 1989; 143: 939-44.

29 Harding C V, Roof R W, Allen P M, Unanue E R. Effects of $\mathrm{pH}$ and polysaccharides on peptide binding to class II major histocompatibility complex molecules. Proc Nat Acad Sci USA 1991; 88: 2740-4.

30 Amin A R, Lakshmi Tamma S M, Oppenheim J D, et al. Specificity of the murine IGD receptor on T cells is for N-linked glycans on IgD molecules. Proc Natl Acad Sci USA 1991; 88: 9238-42.

31 Cherayil B J, Weiner S J, Pillai S. The mac-2 antigen is a galactose-specific lectin that binds IgE. $\mathcal{F}$ Exp Med 1989 170: 1959-72.

32 Katamura K, Iwata M, Mori A, Ishizaka K. Biochemica identification of glycosylation inhibiting factor. Proc Nat Acad Sci USA 1990; 87: 1903-7.

33 Arai K-I, Lee F, Miyajima A, Miyatake S, Arai N, Yokota T. Cytokines: coordinators of immune and inflammatory responses. Annu Rev Biochem 1990; 59: 783-836.

34 Nikaido T, Shimizu A, Ishida N, et al. IL2 receptor structure. Nature 1989; 311: 631-5.

35 Childs R A, Dalchau R, Scudder P, Hounsell E F, Fabre $\mathrm{J}$ W, Feizi T. Evidence for the occurrence of O-glycosidically linked oligosaccharides of poly$\mathrm{N}$-acetyllactosamine type on the human leucocyte common antigen. Biochem Biophy's Res Commun 1983; 110: $424-31$

36 Leahy D J, Axel R, Hendrickson W A. Crystal structure of a soluble form of the human T cell coreceptor CD8 at 2.6 Â resolution. Cell 1992; 68: 1145-62.

37 Parham P. The box and the rod. News and views CD8 and CD4. Nature 1992; 357: 538.

38 Tifft C J, Proia R L, Camerini-Otero R D. The folding and cell surface expression of $\mathrm{CD} 4$ requires glycosylation. $\mathcal{F}$ Biol Chem 1992; 267: 3268-73.

39 Neefjes J J, De Bruijn M L H, Boog C J P. et al. N-linked glycan modification on antigen-presenting cells restores an allospecific cytotoxic T cell response. $N$ Engl $\mathcal{F ~ M e d ~}$ 1990; 10: 533-88.

40 Pascale M C, Malagolin N, Serafini-Cessi F, Migliaccio G, Leone A, Bonatti S. Biosynthesis and oligosaccharide structure of human CD8 glycoprotein expressed in a rat epithelial cell line. 7 Biol Chem 1992; 267: 9940-7.

41 Norment A M, Littman D R. A second subunit of CD8 is expressed in human T cells. EMBO f 1988; 7: 3433-9.

42 Saito H, Kranz D M, Takagaki Y, Hayday A C, Eisen H $\mathrm{N}$, Tonegawa S. Complete primary structure of a heterodimeric T-cell receptor deduced from cDNA sequences. Nature 1984; 309: 757-62.

43 Yoshikai Y, Anatoniou D, Clark S P, et al. Sequence and expression of transcripts of the human $\mathrm{T}$-cell receptor $\beta$-chain genes. Nature 1984; 312: 521-4.

44 Hochstenbach F, Parker C, McLean J, et al. Characterization of a third form of the human $T$ cell receptor $\gamma / \delta . \mathcal{F} \operatorname{Exp} M e d$ 1988; 168: 761-76.

45 Brenner M B, McLean J, Scheft H, et al. Two forms of the T-cell receptor $\gamma$ protein found on peripheral blood cytotoxic T lymphocytes. Nature 1987; 325: 689-94.

46 Krangel M S, Band H, Hata S, McLean J, Brenner M B. Structurally divergent human T cell receptor $\gamma$ proteins

47 Band H, Hochstenbach F, Parker C M, McLean J, Krangel M S, Brenner M B. Expression of human T cell receptor$\gamma \delta$ structural forms. F Immunol 1989; 142: 3627-33.

48 Littman D R, Newton M, Crommie D, et al. Characterization of an expressed CD3 associated T $\gamma$-chain reveal

49 Grossi C E, Ciccone E, Migone N, et al. Human T cells expressing the $\gamma / \delta$ T-cell receptor (TcR-1): C $\gamma 1$-and

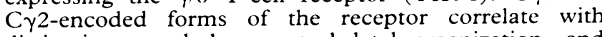
distinctive morphology, cytoskeletal organization, and growth characteristics. Proc Natl Acad Sci USA 1989; 86: growth char

50 Krangel M S, Bierer B E, Devlin P, et al. T3 glycoprotein is functional although structurally distinct on human T-cell receptor $\gamma$ T lymphocytes. Proc Natl Acad Sci USA 1987; 84: 3817-21.

51 Borst J, Alexander S, Elder J, Terhorst C. The T3 complex on human $T$ lymphocytes involves four structurally distinct glycoproteins. F Biol Chem 1983; 258: 5135-41.

52 Oettgen $\mathrm{H} \mathrm{C}$, Terhorst C, Cantley L C, Roseoff P H. Stimulation of the T3-T cell receptor complex induces a membrane-p
40: $583-90$.

53 Wange R L, Tony Kong A-N, Samelson L E. A tyrosinephosphorylated $70-\mathrm{kDa}$ protein binds a photoaffinity analogue of ATP and associates with both the $\zeta$ chain and CD 3 components of the activated $T$ cell antigen receptor. f Biol Chem 1992; 267: 11685-8. 
54 Barnes P F, Grisso C L, Abrams J S, Band H, Rea T H, Modlin R L. $\gamma \delta \mathrm{T}$ lymphocytes in human tuberculosis. Infect Dis 1992; 165: 506-12.

55 Schoel B, Gulle H, Kaufmann S H E. Heterogeneity of the repertoire of $T$ cells of tuberculosis patients and healthy contacts to Mycobacterium tuberculosis antigens separated by high-resolution techniques. Infect Immun 1992; 60: 1717-20

56 Haregewoin A, Soman G, Hom R C, Finberg R W. Human $\gamma \delta^{+} \mathrm{T}$ cells respond to mycobacterial heat-shock protein. Nature 1989; 340: 309-11.

57 O'Brien R L, Happ M P, Dallas A, Palmer E, Kubo R, Born W K. Stimulating of a major subset of lymphocytes expressing $T$ cell receptor $\gamma \delta$ by an antigen derived from expressing $T$ cell receptor $\gamma \delta$ by an antigen derived
mycobacterium tuberculosis. Cell $1989 ; 57: 667-74$.

58 O'Brien R L, Happ M P, Dallas A, et al. Recognition of a single hsp-60 epitope by an entire subset of $\gamma \delta \mathrm{T}$ lymphocytes. Immunol Rev 1991; 121: 155-70.

59 Born W, Hall L, Dallas A, et al. Recognition of a peptide antigen by heat shock-reactive $\gamma \delta \mathrm{T}$ lymphocytes. Science 1990; 249: 67-9.

60 Langer $T$, Neupert $W$. Heat shock proteins hsp60 and hsp70: their roles in folding, assembly and membrane translocation of proteins. Curr Top Microbiol Immunol 1991; 167: 3-30.

61 Koll H, Guiard B, Rassow J, et al. Antifolding activity of hsp60 couples protein import into the mitochondrial
matrix with export to the intermembrane space. Cell 1992; matrix with $1163-75$.

62 Fisch P, Malkovsky M, Kovats S, et al. Recognition by human V $\gamma / \mathrm{V} \delta 2 \mathrm{~T}$ cells of a GroEL homolog on Daudi Burkitt's lymphoma cells. Science 1990; 250: 1269-73.

63 Rajagopalan S, Mao C, Datta S K. Pathogenic autoantibody-inducing $\gamma / \delta \mathrm{T}$ helper cells from patients with lupus nephritis express unusual $\mathrm{T}$ cell receptors. Clin Immunol Immunopathol 1992; 62: 344-50.

64 Holoshitz J, Koning F, Coligan J E, De Bruyn J, Strober $\mathrm{S}$. Isolation of $\mathrm{CD}^{-} \mathrm{CD}^{-}$mycobacteria-reactive T lymphocyte clones from rheumatoid arthritis synovial lymphocyte clones from rheuma
fluid. Nature 1989; 339: 226-9.

65 van Eden W, Thole J E R, van der Zee R, et al. Cloning of the mycobacterial epitope recognized by $T$ lymphocytes in adjuvant arthritis. Nature 1988; 331: 171-3.

66 Haregewoin A, Singh B, Gupta R S, Finberg R W. A mycobacterial heat-shock protein-responsive $\gamma \delta \mathrm{T}$ cell clone also responds to the homologous human heat-shock protein: a possible link between infection and autoimmunity. F Infect Dis 1991; 163: 156-60.

67 Quayle A J, Black Wilson K, Le S G, et al. Peptide recognition, $T$ cell receptor usage and HLA restriction elements of human heat-shock protein (hsp) 60 and mycobacterial $65-\mathrm{kDa}$ hsp-reactive $\mathrm{T}$ cell clones from mycobacterial $65-\mathrm{kDa}$ hsp-reactive $\mathrm{T}$ cell clones from rheumatoid

68 Crick F D, Gatenby P A. Limiting-dilution analysis of T cell reactivity to mycobacterial antigens in peripheral blood and synovium from rheumatoid arthritis patients. Clin Exp Immunol 1992; 88: 424-9.

69 Life P F, Bassey E O E, Hill Gaston J S. T-cell recognition of bacterial heat-shock proteins in inflammatory arthritis. Immunol Rev 1991; 121: 113-35.

70 Res P C M, Telgt D, van Laar J M, Pool M O, Breedveld $F$, de Vries $R$ R P. High antigen reactivity in mononuclear cells from sites of chronic inflammation. mononuclear cells from $1990 ; 336: 1406-8$.

71 Kaufmann S H E. Heat shock proteins and autoimmunity: fact or fiction? The evidence from animal models suggesting the involvement of heat shock protein I autoimmune disease is supported by some, but not all, data from autoimmune disease patients. Current Biology 1991; 1: 359-61.

72 Rippmann F, Taylor N R, Rothbard J B, Green N M. A hypothetical model for the peptide binding domain of hsp 70 based on the peptide binding domain of HLA. EMBO f 1991; 10: 1053-9.

73 Hounsell E F, Renouf D V, Liney D, Dalgleish A G Habeshaw J. A proposed molecular model for the carboxyl terminus of HIV-1 gp120 showing structural carboxyl terminus of $\mathrm{HiV}-1$ gp 120 showing structural alloepitope. Mol Aspects Med 1991; 12: 283-96.

74 Kirchner H, Brehm G, Nicklas W, Beck R, Herbst F Biochemical characterisation of the $T$-cell mitogen derived from Mycoplasma arthritidis. Scand $\mathcal{f}$ Immunol 1986; 24: 245-9.

75 Atkin C L, Cole B C, Sullivan G J, Washburn L R, Wiley B B. Stimulation of mouse lymphocytes by a mitogen derived from Mycoplasma Arthritidis. F Immunol 1986; 137: 1581-9.

76 Paliard X, West S G, Lafferty J A, et al. Evidence for the effects of a superantigen in rheumatoid arthritis. Science 1991; 253: 325-9.

$77 \mathrm{He} \mathrm{X}$, Goronzy J, Weyand C. Selective induction of rheumatoid factors by superantigens and human helper $\mathrm{T}$ cells. $\mathcal{F}$ Clin Invest 1992; 89: 673-80.

78 Holoshitz J, Vila L M, Keroack B J, McKinley D R, Bayne N K. Dual antigenic recognition by cloned human $\gamma \delta \mathrm{T}$ cells. $\mathcal{f}$ Clin Invest 1992; 89: 308-14.

79 Olive C, Gatenby P A, Serjeantson S W. Variable gene usage of $T$ cell receptor $\gamma$ - and $\delta$-chain transcripts expressed in synovia and peripheral blood of patients with rheumatoid arthritis. Clin Exp Immunol 1992; 87: 172-7.

80 Doherty P J, Yang S X, Laxer R M, Silverman E D, Inman $R$, Pan S. Evidence for clonal expansion of $T$ cell receptor $\mathrm{V} \gamma \mathrm{II}^{+} \mathrm{T}$ cells in the synovial fluid of patients with arthritis. f Immunol 1992; 149: 295-9.

81 Kabelitz D, Bender A, Schondelmaier S, Schoel B Kaufmann S H E. A large fraction of human peripheral blood $\gamma / \delta \mathrm{T}$ cells is activated by Mycobacterium tuberculosis but not by its $65-\mathrm{kD}$ heat shock protein. $\mathcal{f}$
Exp Med 1990; 171: 667-79.

82 Orme I M, Miller E S, Roberts A D, et al. T lymphocytes mediating protection and cellular cytolysis during the course of Mycobacterium tuberculosis infection. Evidence for different kinetics and recognition of a wide spectrum of protein antigens. F Immunol 1992; 148: 189-96.

83 Kabelitz D, Bender A, Prospero T, Wesselborg S, Janssen $\mathrm{O}$, Pechhold K. The primary response of human $\gamma / \delta^{+} \mathrm{T}$ cells to Mycobacterium tuberculosis is restricted to $\mathrm{V}_{\gamma}$ 9-bearing cells. $\mathcal{F}$ Exp Med 1991; 173: 1331-8.

84 Casorati G, de Libero G, Lanzavecchia A, Migone N. Molecular analysis of human $\gamma / \delta$ clones from thymus and peripheral blood. f Exp Med 1989; 170: 1521-30.

85 Rust C J J, Verreck F, Vietor H, Koning F. Specific recognition of staphylococcal enterotoxin $\mathrm{A}$ by human $\mathrm{T}$ cells bearing receptors with the $\mathrm{V}_{\gamma} 9$ region. Nature 1990 346: $572-4$.

86 Johnson H M, Russell J K, Pontzer C H. Staphylococcal enterotoxin microbial superantigens. FASEB f 1991; 5 2706-12.

87 Pfeffer K, Schoel B, Plesnila N, et al. A lectin-binding, protease-resistant mycobacterial ligand specifically activates $\mathrm{V}_{\gamma} 9^{+}$human $\gamma \delta \mathrm{T}$ cells. $\mathcal{F}$ Immunol 1992; 148: 575-83.

88 Correa I, Bix M, Liao N-S, Zijlstra M, Jaenisch R, Raulet D. Most $\gamma \delta \mathrm{T}$ cells develop normally in $\beta_{2}$-microglobulindeficient mice. Proc Natl Acad Sci USA 1992; 89: 653-7.

89 Pereira P, Zijlstra M, McMaster J, Loring J M, Jaenisch R Tonegawa $S$. Blockade of transgenic $\gamma \delta \mathrm{T}$ cell
development in $\beta_{2}$-microglobulin deficient mice. $E M B O$ development in $\beta_{2}-$.

90 Vidovic D, Roglic M, McKune K, Guerder S, MacKay C, Dembic $Z$. Qa-1 restricted recognition of foreign antigen by a $\gamma \delta$ T-cell hybridoma. Nature $1989 ; 340: 646-50$.

91 Bucy R P, Chen C-L H, Cooper M D. Tissue localization and CD8 accessory molecule expression of T $\gamma \delta$ cells in humans. F Immunol 1989; 142: 3045-9.

92 Christmas S E. Cytokine production by $\mathrm{T}$ lymphocyte bearing the gamma-delta $\mathrm{T}$ cell antigen receptor. Chem Immunol 1992; 53: 32-46.

93 Morita C T, Verma S, Aparicio P, Martinez-A C, Spits $H$ Brenner M B. Functionally distinct subsets of human $\gamma / \delta$ T cells. Eur f Immunol 1991; 21: 2999-3007. 